\title{
CRISIS Y CAMBIO EN LA MONTAÑA IBÉRICA CASTELLANA. ESTUDIO DE DOS COMARCAS CON MARCADOS CONTRASTES GEOGRÁFICOS: PINARES Y TIERRAS ALTAS ${ }^{1}$
}

\author{
Jesús María BACHILLER MARTÍNEZ \\ Universidad de Valladolid
}

Recibido: $24 / 03 / 2010$

Aceptado: 18/04/2010

RESUMEN: En este artículo se exponen los cambios socioeconómicos experimentados por dos comarcas de montaña situadas en el sector septentrional de la cordillera Ibérica: Tierras Altas, al norte de la provincia de Soria, y Pinares, en el noroeste de Soria y sureste de la provincia de Burgos. Son dos comarcas muy próximas entre sí, pero con modelos de organización muy diferentes, debido al peso de los factores históricos. La actual crisis ha afectado de distinta forma a los dos espacios, pero ha generado respuestas comunes basadas en la valoración de los recursos locales.

$P A L A B R A S C L A V E$ : actividad ganadera; paisaje tradicional; explotación forestal; industria de la madera; despoblación; espacios naturales.

CRISIS AND CHANGE IN THE IBERIAN MOUNTAINS OF CASTILE. A STUDY OF TWO ZONES WITH MARKED GEOGRAPHICAL CONTRASTS: PINE FORESTS AND UPLANDS

ABSTRACT: This This article studies the socioeconomic changes experienced by two mountain areas located in the northern sector of the Iberian Mountains: Tierras Altas, in the north of Soria Province, and Pinares, in the north-west of the Soria Province and the south-east of Burgos Province. Both areas are very close to each other, but they display very different organization models, due to diverging historical factors. The present crisis has affected both spaces very differently too, but it has also generated common answers based in the reappraisal of their local resources.

KEY WORDS farming sector; traditional landscape; forestry business; timber industry; population decline; natural spaces.

\footnotetext{
${ }^{1}$ Este artículo se enmarca en el Proyecto de Investigación «Dinámica socioeconómica y articulación territorial de las montañas interiores en España. Experiencias y orientaciones para el desarrollo sostenible y la política de cohesión territorial» (Referencia SEJ2007-67655-C05-01), financiado por el Ministerio de Educación y Ciencia.
} 
CRISE ET CHANGEMENT DANS LA BRANCHE CASTELLANE DE LA CHAÎNEIBÉRIQUE. ÉTUDE DE DEUX RÉGIONS AUX CONTRASTES GÉOGRAPHIQUES MARQUÉS PINÈDES ET HAUTES TERRES

$\boldsymbol{R} E \boldsymbol{E} \boldsymbol{S} \boldsymbol{U} \boldsymbol{M}$ : Nous présentons dans cet article les changements socio-économiques de deux départements de montagne placés dans le secteur septentrional de la cordillère ibérique : HautesTerres, dans le nord de la province de Soria, et Pinares dans le nord-ouest de Soria et sud-est de la province de Burgos. Ce sont deux départements très proches géographiquement, mais ayant des modèles d'organisation très distincts, et cela en raison des facteurs historiques. La crise actuelle a affecté de manière différente ces deux espaces, mais elle a générée des réponses communes basées sur l'évaluation de leurs ressources locales.

MOTS-CLÉS: élevage, paysage traditionnel, exploitation forestière, industrie du bois, dépeuplement, espaces naturels.

CRISE E MUDANÇA NA MONTAÑA IBÉRICA CASTELHANA. ESTUDO DE DUAS COMARCAS COM MARCADOS CONTRASTES GEOGRÁFICOS DEFINIDOS: "PINARES" E "TIERRAS ALTAS"

RESUMO: Neste artigo apresentam-se as mudanças socioeconômicas vivenciadas por dois distritos de montanha localizados no setor norte da cordilheira Ibérica: outeiros, ao norte da província de Soria, e pinheirais, no noroeste de Soria e no sudeste da província de Burgos . Estas duas regiões muito próximas entre sí, mas com modelos organizacionais muito diferentes, tendo em conta a importância de fatores históricos. A crise atual tem afetado de maneira diferente os dois espaços, mas as respostas comuns mas tem gerado respostas comuns com base na avaliação dos recursos locais.

PALAVRAS CHAVE: trabalho com o gado; paisagem tradicional; atividade madeireira; indústria madeireira; despovoamento; zonas naturais.

\section{INTRODUCCIÓN}

Las consecuencias derivadas de la crisis de las formas de organización tradicional de las zonas de montaña en España han desencadenado procesos territoriales y dinamismos enormemente dispares, que han acabado configurando estructuras y modelos muy específicos en los distintos territorios, en función de las nuevas orientaciones y formas de explotación introducidas. Todo ello se ha traducido en la creación de una tipología plural de paisajes y áreas de montaña. Un buen exponente de las diferentes dinámicas emprendidas por los espacios rurales ante las nuevas situaciones socioeconómicas, lo constituye la evolución de dos comarcas de la montaña ibérica castellana, Tierras Altas y Pinares, que, pese a su proximidad, han generado procesos bien contrastados. Tierras Altas es una pequeña comarca situada al norte de la provincia de Soria, limítrofe con la comunidad de La Rioja; la comarca de Pinares, comprende el Noroeste de Soria y el Sureste de la provincia de Burgos. A partir de la estructura socioeconómica y la configuración del espacio derivada de los aprovechamientos tradicionales, en este artículo se estudia la distinta respuesta que cada comarca ha dado a la etapa crítica de las economías rurales en el tercer cuarto del siglo XX, de qué 
manera han evolucionado las estructuras resultantes y cuáles son las nuevas estrategias de desarrollo rural.

\section{DOS COMARCAS BIEN DEFINIDAS DESDE EL PUNTO DE VISTA FÍSICO Y SOCIOECONÓMICO}

Si los estudios de comarcalización en la comunidad de Castilla y León han resultado difíciles, en la provincia de Soria esta tarea puede considerarse especialmente compleja por las peculiaridades geográficas que afectan a su territorio. Sin embargo, existen varios sectores en los espacios serranos del norte de la provincia que sí tienen unas características bastante bien definidas desde el punto de vista físico y socioeconómico, y que dan nombre a dos comarcas bien delimitadas y bien conocidas, Tierras Altas y Pinares. La comarca de Tierras Altas ha estado unida desde hace varias décadas a la vecina comarca del Valle del Tera, a pesar de sus evidentes diferencias, debido al conocido estudio: comarcalización agraria de España, del Ministerio de Agricultura, que ha servido de referencia para muchos otros documentos y análisis. En este proyecto se han separado por considerar que son espacios con trayectorias y problemáticas distintas. El límite se ha establecido en la sierra de Montes Claros o Sierra de Alba, que, con una altitud cercana a los $1800 \mathrm{~m}$., circunscribe la comarca por el oeste y marca diferencias geográficas significativas entre el oeste y el este de la misma. Por el norte las sierras del Camero Viejo, Hayedo de Santiago, San Cristóbal y otras menores la separan de oeste a este de la provincia de La Rioja, con altitudes que descienden de los 1800 a los $1300 \mathrm{~m}$. Por el este, la sierra de Alcarama, que vuelve a superar los $1500 \mathrm{~m}$., y otras de menor vigor la delimitan de la tierra de Ágreda. Por el sur, la sierra del Almuerzo, por encima de los 1500 $\mathrm{m}$., y una serie de elevaciones entre los 1100 y $1200 \mathrm{~m}$. constituyen la divisoria de las vertientes que dan al valle del Duero.

Se trata de una comarca de media montaña, en la que la mayor parte de las tierras se encuentran por encima de los $1100 \mathrm{~m}$. Solo algunos valles estrechos, que descienden al valle del Ebro por el norte y este, se encuentran situados por debajo de los $1000 \mathrm{~m}$. La mayoría del espacio vierte sus aguas al Ebro, con una divisoria bien delimitada por la línea de cumbres que forman las sierras de Montes Claros, la Calva y sierra del Almuerzo. Los términos de algunos municipios dejan algunas vertientes meridionales que drenan al Duero por la comarca del Valle o la Tierra de Soria, generalmente a través de arroyos o barrancos, y algunos pequeños ríos como es el caso del Merdancho. La comarca de Tierras Altas queda estructurada entonces en tres valles principales de dirección suroeste-noreste, que recorren los ríos Cidacos, Linares y Alhama. Todo el conjunto comarcal alcanza una superficie de $867,19 \mathrm{Km} 2$, lo que supone tan solo un $8,4 \%$ de la superficie de la provincia, distribuida actualmente desde el punto de 
vista administrativo en 25 términos municipales, que tienen a su vez 57 núcleos de población. Comprende aproximadamente las antiguas comunidades de villa y tierra de Yanguas, al oeste, San Pedro Manrique en el centro y Magaña al este.

Mapa 1. Localización del área de estudio.
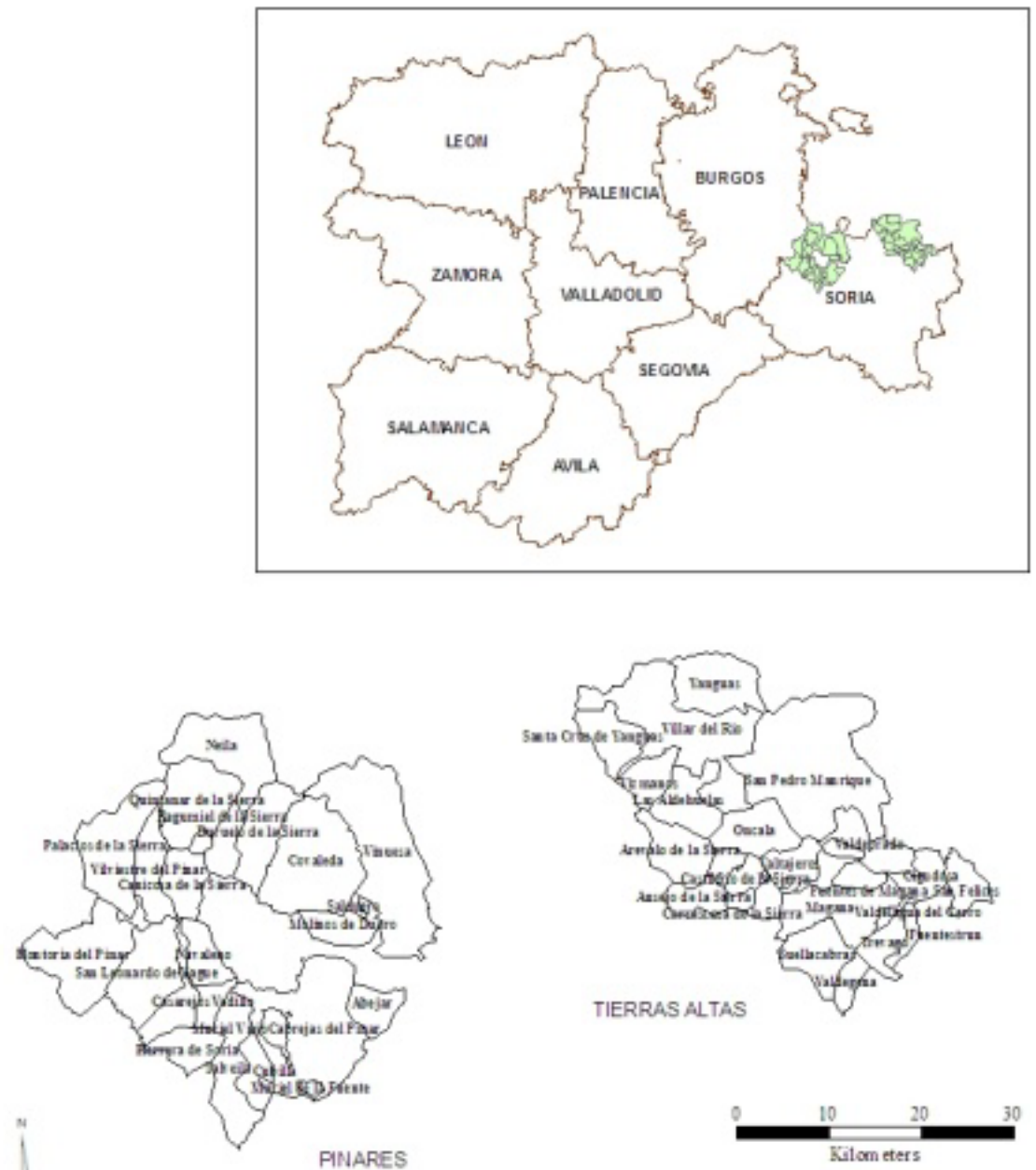

Su elevada altitud media, su topografía accidentada y su clima extremo condicionan la organización del espacio, mucho más orientada a la producción ganadera que a la agrícola. Más del $60 \%$ del espacio agrario está dedicado a pastos, que tradicionalmente han mantenido una explotación ganadera lanar con 
gran importancia de la trashumancia. Este sistema se sostuvo con cierto desarrollo a lo largo de varios siglos en función de las directrices económicas del país, que tenía en el comercio de la lana uno de sus pilares fundamentales. En la actualidad, este sistema de explotación se ha reducido drásticamente, lo cual ha tenido, como cabe imaginar, profundas implicaciones geográficas.

La comarca de Tierras Altas se puede considerar todo un referente de los problemas que afectan a una gran parte de las áreas de montaña del interior peninsular, al constituir una verdadera punta de lanza en el fenómeno de la despoblación, tan debatido en la comunidad de Castilla y León, y sufrir como ninguna los efectos del aislamiento, el debilitamiento socioeconómico y la desarticulación territorial.

La comarca de Pinares se encuentra situada a tan solo $30 \mathrm{~km}$ de la de Tierras Altas, en el borde suroeste del llamado dominio de la Sierra de Cameros. Ocupa el sector noroccidental de la provincia de Soria y mantiene las mismas características en el sureste de la de Burgos, lo que nos ha inclinado a extender el área de estudio por la vecina provincia burgalesa, a pesar de las dificultades añadidas que ello entraña. Ambos sectores comparten muchos caracteres geográficos y participan conjuntamente, desde hace 20 años, en un programa Leader conocido como ASOPIVA.

La comarca está bien delimitada al norte por las sierras de la Demanda y Urbión, al oeste por la depresión sinclinal del río Lobos, al sur por la sierra de Cabrejas y al este por la sierra del Portillo de Pinochos, que da paso a la comarca del Valle. Se trata, como Tierras Altas, de una comarca de media montaña, configurada por diversas alineaciones montañosas de dirección dominante oesteeste, que descienden en altitud de norte a sur, aunque ningún punto se sitúa por debajo de los $1000 \mathrm{~m}$ de altura. Se pueden distinguir dos sectores diferenciados: el sector septentrional forma el eje central, el más elevado, que comprende el entorno de las sierras de la Demanda y Urbión y que se prolonga por las provincias de Burgos y La Rioja con altitudes que superan los $2000 \mathrm{~m}$.; el segundo sector estaría formado por la orla ibérica interior, con dos alineaciones: en el centro, la sierra del Resomo, que alcanza los $1500 \mathrm{~m}$., y al sur la sierra de Cabrejas, que apenas llega a los $1400 \mathrm{~m}$. Entre estas alineaciones se abren algunos valles y rellanos por donde transcurre la red hidrográfica y se alinea también la red de asentamientos. Cabe destacar los rellanos de Duruelo y Covaleda que atraviesa el Duero y los valles del Ebrillos y el Revinuesa. El principal es el valle del Duero, que recorre la comarca desde la vertiente sur de la sierra de Urbión. Desciende rápidamente hasta Duruelo de la Sierra y toma una dirección oeste-este hasta las proximidades de Soria, donde describe la conocida "curva de ballesta" que Machado cantó en uno de sus más conocidos poemas. 
La comarca de Pinares es una de las que tiene las características mejor definidas de la provincia de Soria y la que ofrece una simbiosis más estrecha entre el medio físico, la población y las actividades económicas. Con una superficie de $974 \mathrm{Km}^{2}$, más del $75 \%$ está ocupada por una masa bastante homogénea de pino silvestre, que ha sido desde hace décadas su principal fuente de riqueza. También se distingue por algunos rasgos históricos, como es el de la propiedad de los montes, que son de uso comunal, del que se benefician todos los vecinos por el simple hecho de cumplir unas determinadas normas de arraigo y residencia en el pueblo. Todo ello ha sido un factor de desarrollo económico y estabilidad demográfica.

\section{UNA TRAYECTORIA DEMOGRÁFICA CONTRASTADA: EL AGOTAMIENTO DE TIERRAS ALTAS FRENTE A LA ESTABILIDAD DE LA COMARCA DE PINARES}

La evolución demográfica en las dos comarcas objeto de estudio muestra algunos datos relevantes para entender las relaciones entre población y recursos, y sus implicaciones geográficas. La comarca de Tierras Altas, por un lado, constituye todo un referente de la despoblación en los espacios de montaña españoles, una especie de punta de lanza de los procesos de abandono económico y demográfico que sufren muchas áreas de montaña de nuestro país (MARTíN JIMÉNEZ, 2008). Por eso, tomarle el pulso y hacer un análisis de los nuevos conceptos de población que deben manejarse para este tipo de comarcas, así como las consecuencias que todo ello plantea está plenamente justificado. La comarca de Pinares, por el contrario, destaca por el mantenimiento de los niveles de población de principios del siglo XX, algo bastante infrecuente en los espacios de montaña del interior peninsular.

\section{III.1. El debate sobre la despoblación y la situación en Tierras Altas}

En Tierras Altas el fenómeno de la despoblación se inició ya a principios del siglo XX, como ocurrió también en otros espacios de la montaña soriana, sobre todo del sur y suroeste (BACHILLER MARTíNEZ, 1996). El frágil equilibrio población/recursos comenzó a romperse en la segunda década del siglo, cuando la emigración empezó a superar el crecimiento natural de la población. De este modo, en 1950, la población de hecho de Tierras Altas ya se había recortado más de un $8 \%$ respecto a la de 1910 , a pesar de las especiales circunstancias que se dieron en España después de la guerra civil, razón por la cual muchos municipios españoles lograron en ese censo el techo demográfico del siglo XX. En los años 50 se acelera el proceso y en los 60 y 70 el nuevo contexto socioeconómico hundió la población dejando sumida la comarca en un círculo vicioso de difícil salida. La crisis de la ganadería tradicional, principal recurso de la comarca, está detrás de este derrumbe. La agonía se ha prolongado práctica- 
mente hasta la actualidad ante la falta de alternativas económicas. Actualmente sólo están censados 18 de cada 100 vecinos de 1950. La comarca cuenta con una población según el padrón de 2009, de 2048 habitantes, distribuidos en 57 núcleos de población, lo que supone una media de 36 habitantes por cada pueblo, con índices de envejecimiento altísimos. La densidad media es de 2,3 $\mathrm{hab} / \mathrm{km}^{2}$.

El fenómeno de la despoblación se ha convertido en una preocupación que ha emergido en el debate político de la comunidad de Castilla y León en los últimos años. El gobierno regional presentó en las cortes regionales, en febrero de 2009, la Agenda de la Población, con 108 actuaciones en distintos ámbitos. Hay que reconocer que este debate llega tarde y se ha topado con una realidad profundamente alterada y difícil de recuperar. La despoblación es un fenómeno complejo en el que interviene una multiplicidad de factores y debe valorarse teniendo en cuenta una gran diversidad de elementos, y no solo la evolución demográfica global de una comarca. Influye el tamaño de las poblaciones, y no de los municipios, su grado de relación interna y de integración con el exterior, su nivel de infraestructuras y servicios, el comportamiento a escala comarcal, su dinamismo económico y social, el grado de correspondencia entre despoblación y abandono, etc.

Aunque ha irrumpido en los últimos años, la despoblación es un fenómeno que se ha fraguado a lo largo de muchas décadas, aunque ahora asistamos a su desenlace en muchas comarcas. El fuerte ajuste de población que habían experimentado las áreas rurales en el tercer cuarto del siglo XX, con sus profundas secuelas, llevó a principios de los años 80 a plantear un debate sobre la existencia de un umbral mínimo de población para poder conseguir una situación de equilibrio demográfico. La dotación de infraestructuras y servicios necesaria para satisfacer las demandas sociales de la población y la consecución de un mínimo de calidad de vida precisan una determinada escala de población. La despoblación es el resultado de un proceso de ajuste en el que las poblaciones rurales han llegado a su punto de equilibrio en relación a sus recursos.

En la actualidad, los conceptos de población están cambiando, en la medida que ha cambiado el entorno en que se mueven las relaciones entre los espacios rurales y urbanos, que ha favorecido una mayor vinculación y movilidad de la población entre ambos. Todo ello matiza los conceptos de despoblación, en función de nuevos parámetros como el nivel de integración de los espacios rurales o el tamaño de población alcanzado en distintas partes del año. En cualquier caso, parece claro que la consecución de un cierto pulso económico y social no puede alcanzarse de una forma individualizada, tan recurrente en el medio rural y con consecuencias tan negativas, sino con una visión comarcal y con nuevas bases para la ordenación del territorio. 
Figura 1. Evolución demográfica en los distintos censos y padrones.

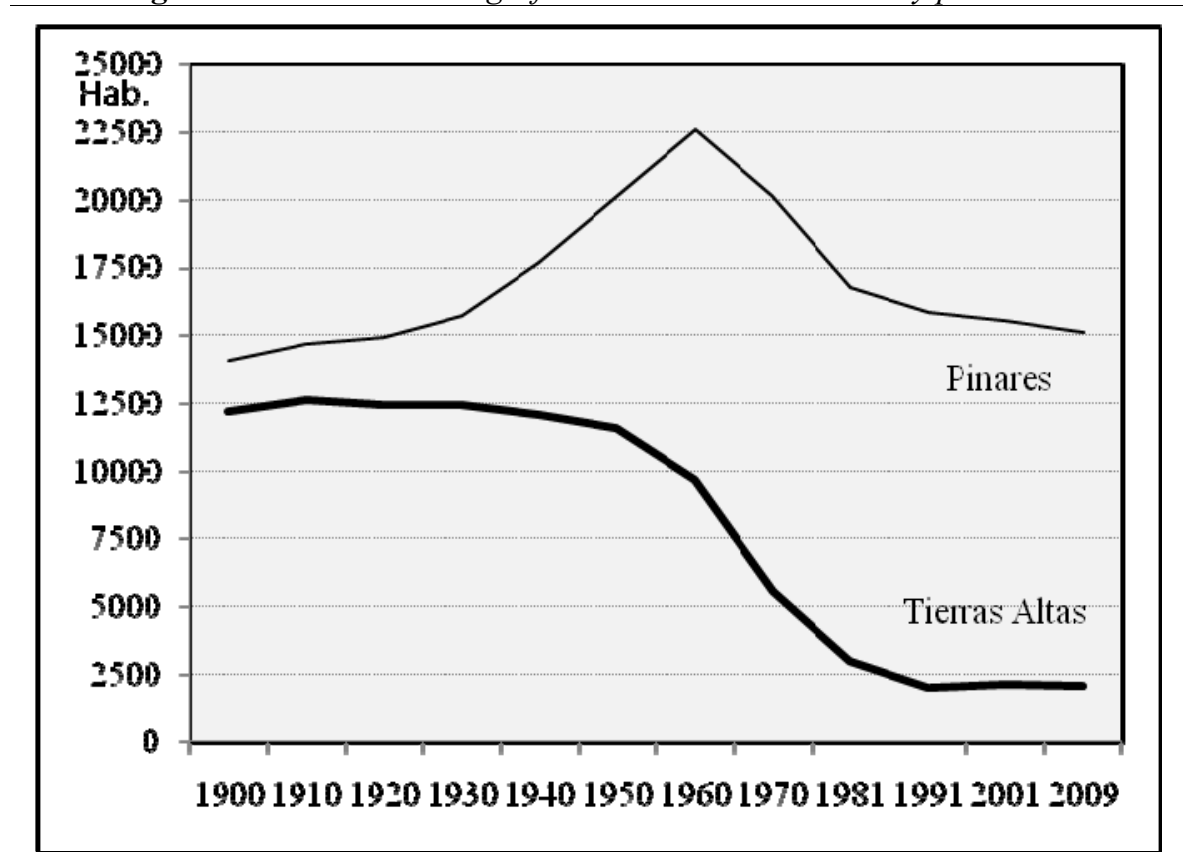

FUENTE INE: Elaboración propia

El caso de Tierras Altas constituye un ejemplo extremo de despoblación y de aislamiento dentro de las zonas de montaña interior, hasta el punto de erigirse en todo un referente de la espiral en la que están inmersas muchas áreas de montaña. No solo la población es escasa, poco más de 2000 habitantes, sino que se reparte en 57 núcleos, dos tercios de los cuales tiene menos de 25 vecinos censados. Solo dos núcleos de población superan los 100 habitantes, San Pedro Manrique, que es la cabecera de comarca, con 542, y Yanguas con 120. Un $35 \%$ de la población tiene más de 65 años y solo un $6 \%$ menos de 15 . Las relaciones internas siguen siendo difíciles y las comunicaciones con la capital soriana han mejorado, pero aún así se tarda unos 45 minutos de viaje. La evolución del fenómeno de la despoblación en Tierras Altas llega a tal punto que puede diseñarse una taxonomía de núcleos de población en función de su grado de ocupación. Podemos establecer 5 categorías de pueblos: Los que están habitados permanentemente, los que cobran vida los fines de semana, los que se abren en temporada de verano, los que limitan su vida a las fechas de celebración de las fiestas patronales y los deshabitados.

En toda la comarca se observa, por lo general, una resistencia de todos los núcleos a la despoblación definitiva y para ello se utilizan todos los medios posi- 
bles, incluidos programas de repoblación rural o el recurso a programas televisivos para introducir familias. En esta lucha contra el abandono se implican muchas familias emigrantes, que no quieren perder el vínculo con su tierra. Se han arreglado casas, con las consiguientes medidas de protección, se han formado asociaciones y se intenta mantener un mínimo de infraestructura en el casco urbano. También se ha generado un tipo de movimiento turístico en torno a los pueblos abandonados, que podría aprovecharse para aumentar el atractivo de la comarca. En conjunto, la distribución de poblaciones en las distintas categorías, según las informaciones locales, quedaría como sigue:

$\checkmark$ Poblaciones habitadas permanentemente: Son 32 en total, con al menos un vecino residiendo en el pueblo.

$\checkmark$ Pueblos habitados los fines de semana: Diustes, Camporredondo, Malla, Cecilia, Valduérteles, Taniñe.

$\checkmark$ Pueblos de temporada de verano: Sarnago, Las Fuentes, Armejún, Castillejo, La Vega, Navabellida (en la temporada de la trashumancia).

$\checkmark$ Pueblos habitados solo en las fiestas patronales: Valdecantos, Villarijo, La Mata.

$\checkmark$ Deshabitados: Torretarrancho, El Vallejo, Bea, Acrijos, Funtebella, Valdemoro, Aldealcardo, Lería, Bellosillo, Villaseca Bajera.

El alcance de la despoblación y el envejecimiento demográfico justifican que la comarca haya experimentado una importante corriente inmigratoria procedente del exterior, para cubrir los puestos de trabajo que no quieren los nacionales, sobre todo en el sector agrario y en el de servicio doméstico. Ello explica que la proporción de población extranjera sea muy alta en algunos municipios (18\% en San Pedro Manrique o Yanguas). La llegada de población extranjera contrarresta la salida de población joven y se ha convertido en un factor de estabilidad demográfica en los últimos años, no sin problemas por la falta de viviendas y algunos equipamientos y servicios. Todo ello repercute positivamente en otros indicadores demográficos, como la natalidad, y afecta a algunos servicios básicos, como la educación, que recibe un número creciente de alumnos. Resulta llamativo comprobar cómo el centro agrupado de Tierras Altas, ubicado en San Pedro Manrique, se ha quedado pequeño durante este curso 2009-2010 para acoger el espectacular aumento del número de alumnos.

\section{III.2. La estabilidad demográfica de la comarca de Pinares}

A diferencia de Tierras Altas, la comarca de Pinares representa una de las pocas excepciones dentro de la trayectoria demográfica de la montaña interior. Su 
evolución contrasta asimismo con la que han experimentado muchas áreas de las llanuras cerealistas. La población pinariega prolongó su crecimiento hasta los años 60, al tiempo que se hundía en la mayoría de espacios de montaña. La población creció más de un $60 \%$ ente 1900 y 1960. Los años 60 y 70, que fueron los más críticos en las áreas de montaña españolas, en el caso de la comarca pinariega tuvieron un efecto mucho más amortiguado debido a la creación de empresas dedicadas al aprovechamiento de los recursos locales. De gran importancia fue la industria de aserrío y de segunda transformación para la creación de empleo en la comarca (PINILLOS ET AL., 2005). El aprovechamiento de los recursos forestales autóctonos fue el núcleo en torno al cual se forjó el tejido empresarial de la comarca, factor esencial para el mantenimiento de la población en las últimas décadas del siglo XX. Frente al modelo de poblamiento de Tierras Altas, Pinares se basa en la presencia de pocos núcleos, pero de cierto tamaño, con una mejor dotación de equipamientos y servicios. Los 15.131 habitantes censados en el padrón de 2009 se distribuyen en 27 núcleos de población, con una media de 561 habitantes. La densidad media asciende a $15,6 \mathrm{hab} / \mathrm{km}^{2}$, casi el doble que la media provincial.

La comarca de Pinares presenta una gran singularidad dentro de la montaña ibérica. Su paisaje forestal sorprende por su extensión y continuidad. Las cumbres de Urbión, nevadas gran parte del año, son conocidas por el nacimiento de uno de los ríos más importantes de la península, el Duero, que articula en sus primeros kilómetros este espacio. La claridad del cielo que disfrutamos en esta provincia convierte este punto en un mirador privilegiado para otear uno de los territorios más vastos de la península, el que se extiende desde los Pirineos hasta la Cordillera Central. Estos paisajes se identifican también con su historia y con su cultura, hasta conformar un modelo de organización y un sentimiento de comunidad que se refleja en sus costumbres y tradiciones, en sus actividades económicas y hasta en su forma de entender la vida. Los montes tienen un aprovechamiento comunal. Cada vecino, por el solo hecho de cumplir una serie de requisitos, recogidos en las ordenanzas de cada ayuntamiento, recibe lo que se llama una "suerte de pinos".

El elevado precio de la madera en los años 50 y 60 proporcionó una gran prosperidad a la comarca, cuyas familias podían vivir, prácticamente, de las suertes de pinos, de los trabajos forestales y de la recogida y venta de los hongos que se recolectaban durante el otoño. Las suertes de pinos llegaron a desempeñar una función social de complemento de ingresos en personas mayores con bajas rentas. Surgieron entonces las primeras cooperativas dedicadas a la primera transformación de la madera; estas se fueron extendiendo por los distintos municipios y en algunos, como Duruelo de la Sierra, Covaleda o San Leonado de Yagüe, aparecieron otras empresas de segunda transformación, que 
aportaban mayor VAB a la comarca. A su vez, los hongos han proporcionado también materia prima a varias fábricas conserveras, algunas de ellas con gran tradición exportadora.

Este proceso de transformación, basado en el aprovechamiento de los recursos endógenos, ha sido un factor de estabilidad demográfica. Frente a otras comarcas de montaña como Tierras Altas, al norte, o Sierra de Pela, al sur, que han perdido más del $80 \%$ de sus efectivos en el último medio siglo, Pinares mantiene una población más estable, con un sistema de poblamiento consolidado, que goza de una gran estabilidad.

\section{LA ESTRUCTURA SOCIOECONÓMICA Y LA CONFIGURA- CIÓN DEL ESPACIO DERIVADA DE LOS APROVECHA- MIENTOS TRADICIONALES}

Uno de los aspectos que más sorprende cuando uno recorre estas dos comarcas es el contraste paisajístico tan enorme que existe entre ellas, en tan pocos $\mathrm{km}$. de distancia. Tales contrastes tienen su origen en varios factores: La diferencia de altitud confiere a la comarca de Pinares una mayor energía de relieve y una mayor actividad glaciar y periglaciar, ya que los hielos cuaternarios afectaron en la provincia de Soria por encima de los $1850 \mathrm{~m}$. La impronta glaciar en las cumbres de la Demanda y Urbión han dejado unas huellas de gran valor científico y paisajístico. Las diferencias climáticas y edáficas, no exentas de variaciones internas, influyen en la tipología y desarrollo de las comunidades vegetales, si bien estas se encuentran muy alteradas por los aprovechamientos agrarios tradicionales. La mayor pluviometría de la comarca pinariega admite una mayor evolución de las masas arbóreas frente a la comarca de Tierras Altas, cuyo gradiente de pluviosidad va descendiendo de oeste a este hasta desembocar en los terrenos más áridos y ásperos, con plantas más termófilas, de la antigua comunidad de villa y tierra de Magaña. Las diferencias litológicas establecen también variaciones paisajísticas notables entre distintas unidades de la misma comarca. Pero el factor que más influye en los enormes contrastes paisajísticos de las dos comarcas son los modelos tradicionales de organización y aprovechamiento del espacio agrario (FIGURA 2).

Lo que más caracteriza a Pinares es la presencia de una gran mancha forestal continua, extendida por toda la comarca, que, como su propio nombre indica, está formada principalmente por pino albar (Pinus sylvestris), probablemente originario de la zona. En algunas laderas del norte se mezcla con el rebollo (Quercus pyrenaica) y en las áreas más elevadas con especies más aisladas como el haya (Fagus sylvatica), el abedul (Betula pendula) el tejo (Taxus baccata) y otras especies. Al sur de la comarca, en consonancia con el descenso de los valores pluviométricos, aparece mezclado con el pino resinero (Pinus pinas- 
ter), el pino laricio y dos especies características y de gran desarrollo en la provincia como la sabina albar (Juniperus communis) y el enebro (Juniperus thurifera), según la denominación autóctona. Hasta las primeras décadas del siglo XX la relación entre la superficie forestal y la superficie de pastos no debió diferir mucho, siendo una práctica habitual la quema del monte para la regeneración de los pastizales. Dentro de Pinares había municipios con gran tradición de ganadería trashumante, como es el caso de Vinuesa o Molinos de Duero. Fue seguramente en los años 50 y 60 cuando se logra la mayor expansión del pinar, en una coyuntura en la que el precio de la madera era muy elevado, y permitía vivir a una familia con el cobro de la suerte de pinos y el apoyo de algún trabajo adicional. A mediados del siglo XX, casi el $70 \%$ de la superficie agraria estaba ocupada por el bosque. El sistema de explotación de la madera, basado en la entresaca, permitía mantener una mancha continua, semejante a una gran alfombra verde, formada por un pinar con ejemplares muy heterogéneos en edad y grado de crecimiento.

Figura 2. Paisaje tradicional en Tierras Altas (puerto de Oncala) y Pinares (Duruelo de la Sierra).
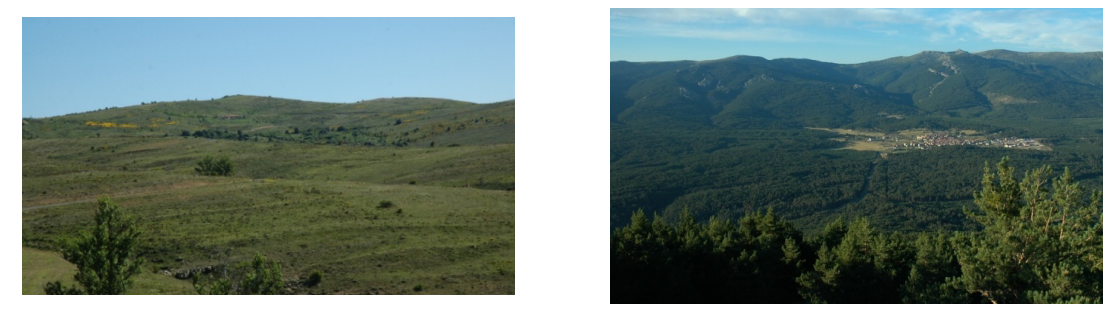

En Tierras Altas, por el contrario, lo que predomina son los pastizales de montaña que, desde la Edad Media y hasta el siglo XIX, han sostenido una importante cabaña lanar, integrada principalmente por la raza merina trashumante. A mediados del siglo XX, el 65\% de la superficie agraria estaba dedicada a pastos o pastizales, aunque esta proporción variaba en función de las características de los términos. En la antigua comunidad de Yanguas, que es el sector más elevado y abrupto, llegaba al 70\%, pero en algunos términos de las comunidades de San Pedro Manrique y Magaña no alcanzaban el 60\%. La superficie cultivada ha sido tradicionalmente escasa, sobre todo en los sectores más montañosos del oeste y norte de la comarca. En 1958 se alcanzó un 28,8\%, si bien en la antigua comunidad de Yanguas solo llegaba al 19\%. Quizá lo más significativo es la meticulosa adaptación al terreno de la agricultura, de manera que el paisaje agrario se organizaba en bancales que, desde los fondos de los valles, ascendían por la vertiente hasta altitudes considerables, que podían llegar hasta los 1400 $\mathrm{m}$. Eran espacios casi enteramente cerealistas (trigo, cebada y centeno), con un sistema de año y vez. De esta forma, los valles de Tierras Altas tenían una or- 
ganización bastante similar, con una estructura en bancales en el fondo y las primeras estribaciones y extensos pastizales que ocupaban las laderas y las cumbres. La presión ganadera debió ser muy fuerte en distintas etapas históricas, puesto que son escasas las manchas de bosque que se conservan y que se reducen a algunos robledales aislados en dehesas y barrancos, un interesante hayedo en el término de Diustes, diversos encinares en las laderas meridionales y un importante acebal en el término de Torrearévalo, recientemente declarado espacio natural protegido. Sirva como ejemplo que, en la tierra de Yanguas, llegaron a contabilizarse en el catastro de la Ensenada un total de 97.601 ovejas, de las cuales el 91\% eran merinas trashumantes (ALCALDE, 2000: 78). Haciendo un cálculo de la superficie de pastos y pastizales, según los datos del catastro, se llega a la conclusión de que pastaban una media de 5 ovejas por ha entre los meses de junio y octubre.

\section{LOS DINAMISMOS ACTUALES Y SUS IMPLICACIONES GEOGRÁFICAS}

La etapa clave en la evolución de las áreas rurales españolas tuvo consecuencias distintas en las dos comarcas, de las que derivaron modelos de organización muy contrastados, que han repercutido en su devenir reciente. Ambos espacios representan la creación de procesos territoriales y dinamismos muy dispares, aunque en los últimos años han adquirido connotaciones comunes por la análoga respuesta a las diferentes situaciones de crisis en las que se han visto inmersas. Así, mientras la comarca de Tierras Altas ha seguido una lenta agonía y ha sido objeto de planes de reestructuración territorial como consecuencia de los procesos de despoblación, Pinares ha desarrollado un cierto tejido económico que le ha conferido una base más sólida para afrontar las nuevas oportunidades de creación de riqueza.

\section{V.1. El declive socio-económico de Tierra Altas y las grandes interven- ciones públicas derivadas del proceso de abandono}

La crisis de la ganadería trashumante y de la agricultura tradicional, el progresivo distanciamiento de las condiciones de vida con respecto a la media y el consiguiente descenso demográfico de muchas pequeñas poblaciones a lo largo de los años 40 y 50 fue el argumento para que en el año 1965 se presentara, por parte del Patrimonio Forestal del Estado, un estudio sobre la reestructuración de la comarca forestal de Yanguas y San Pedro Manrique, que puede enmarcarse dentro de los grandes proyectos de repoblación forestal que se plantearon en esa época para distintas provincias españolas. Con independencia de las justificaciones y los, cuanto menos curiosos, análisis y planteamientos que se hacían en ese estudio, sorprende la visión del medio y la capacidad de cambiar las cosas a gran escala que tenían los ingenieros forestales en aquella época, de espaldas a 
la sociedad local. La progresiva despoblación y el bajo nivel social de estas áreas de montaña, en orden a no retrasar ni estancar ninguno de los sectores productivos del país, justificaban el macro-proyecto de intervención pública, que planteaba una reordenación del poblamiento (las 42 localidades existentes se concentrarían en seis núcleos), una reorganización de la propiedad, una reestructuración meticulosa, hasta límites insospechados, de todos los sectores económicos, incluidos los servicios, $\mathrm{y}$, en especial, una repoblación forestal masiva, que afectaría a más de 28.000 ha repartidas en 22 poblaciones de los actuales términos de Las Aldehuelas, San Pedro Manrique, Santa Cruz de Yanguas, Villar del Río, Vizmanos y Yanguas.

Las consecuencias directas de este plan fue el cambio de vocación productiva de amplios espacios tradicionales y la transformación paisajística de todo el sector norte de la comarca (FIGURA 3). La valoración que se puede hacer de una actuación de tal envergadura resulta complicada, sin el apoyo de unos estudios más precisos. Estoy de acuerdo con muchas de las reflexiones que se efectúan en el estudio de Francis Chanvelier sobre la repoblación forestal en la provincia de Huesca (CHANVELIER, 1990, p. 143), que podrían aplicarse al caso de Tierras Altas de Soria. Sin embargo, con cierta perspectiva temporal, efectuar un juicio de valor resulta difícil, puesto que no sabemos, por ejemplo, cual habría sido el resultado si el tipo de actuación hubiera sido otro distinto, más en consonancia con los intereses de las poblaciones locales. Por otra parte, efectuar una valoración objetiva, alejada de cualquier prejuicio, requeriría establecer comparaciones, en todos los planos, medioambiental, socioeconómico, demográfico, etc. con la evolución que han tenido otras comarcas vecinas en las que no se ha producido tal intervención. Existe una creencia extendida de que el plan forzó a los vecinos a emigrar y que, por tanto, fue una causa directa de la despoblación, en contra de algunos de sus principios inspiradores. Si nos fijamos en la evolución demográfica de otros sectores de la comarca, se comprueba que la población hubiera emigrado igual, imbuida por la política general del país. En todo caso, los recursos económicos adicionales de los que dispusieron los vecinos con la venta de las tierras y los trabajos en las labores de reforestación, no hicieron más que facilitar el éxodo. Los resultados de la reforestación, por otra parte, han sido desiguales según las zonas, y su rendimiento económico no resulta fácil en un sector tan internacionalizado como el de la madera. No obstante, hay que empezar a valorar como muy importantes los ingresos producidos por la caza, que resultan decisivos para sostener la infraestructura turística de la comarca, y los derivados de la micología, que hoy tratan de regularse en toda la provincia. 
Figura 3. Transformación paisajística en cerro Santo (Yanguas). Marzo 1969; Noviembre 1969; Abril 1991 y Junio 2009.
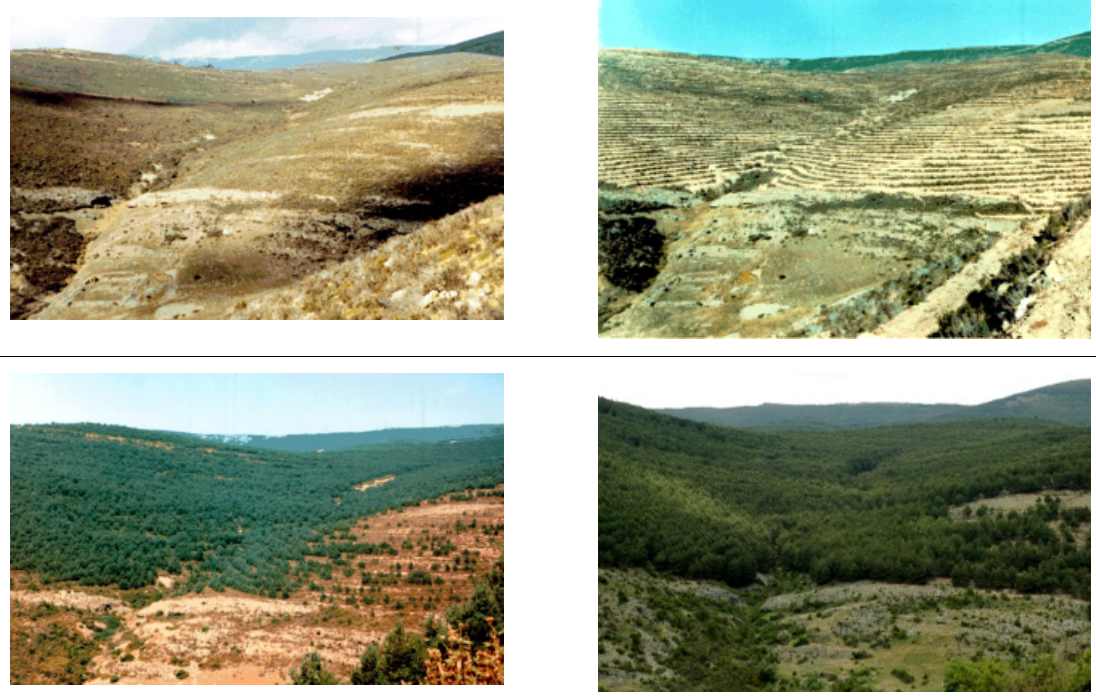

Las tres primeras fotos han sido cedidas por la Delegación Territorial de M.A. de Soria

La intensa despoblación sufrida en toda la comarca ha conducido inexorablemente a un proceso de abandono, que tiene unos impactos geográficos evidentes. El número de explotaciones agrarias se redujo a la mitad entre el censo agrario de 1982 y el de 1999. La evolución de los aprovechamientos (FIGURA 4) revela algunos datos interesantes. La superficie forestal refleja las repoblaciones masivas de los años 60 y las posteriores de los años 90 y primera década de siglo, sobre todo en terrenos públicos. Las tierras de cultivo se fueron recortando desde los años 60 y en los últimos años se han vuelto a incrementar a costa de los pastizales, no por su rentabilidad económica, sino en función de las ayudas de la PAC. La superficie dedicada a pastos y pastizales ha descendido sustancialmente en los últimos años debido al hundimiento de la cabaña ganadera lanar, que ha pasado de 71.573 cabezas en el año 1992 a tan solo 17.787 en el censo ganadero de 2008.

Si la sobreexplotación en el pasado condujo a la degradación de muchos conjuntos ambientales, en la actualidad el descenso de la presión ganadera ha supuesto una rápida evolución de muchos pastizales hacia un progresivo desarrollo del matorral, en el que progresan diversas especies como la aliaga (Genista scorpius), el brezo (Erica arbórea) o el rosal silvestre (Rosa canina). Por su parte, la despoblación ha supuesto el abandono del sistema tradicional de culti- 
vo en bancales, tan extendido por toda la comarca, del que solo se aprovechan ahora los más accesibles. Los llamados pueblos abandonados jalonan el paisaje de Tierras Altas ofreciendo una imagen romántica, pero a la vez expresiva del declive de un modelo rural.

Figura 4. Evolución de la distribución de las superficies en Tierras Altas.

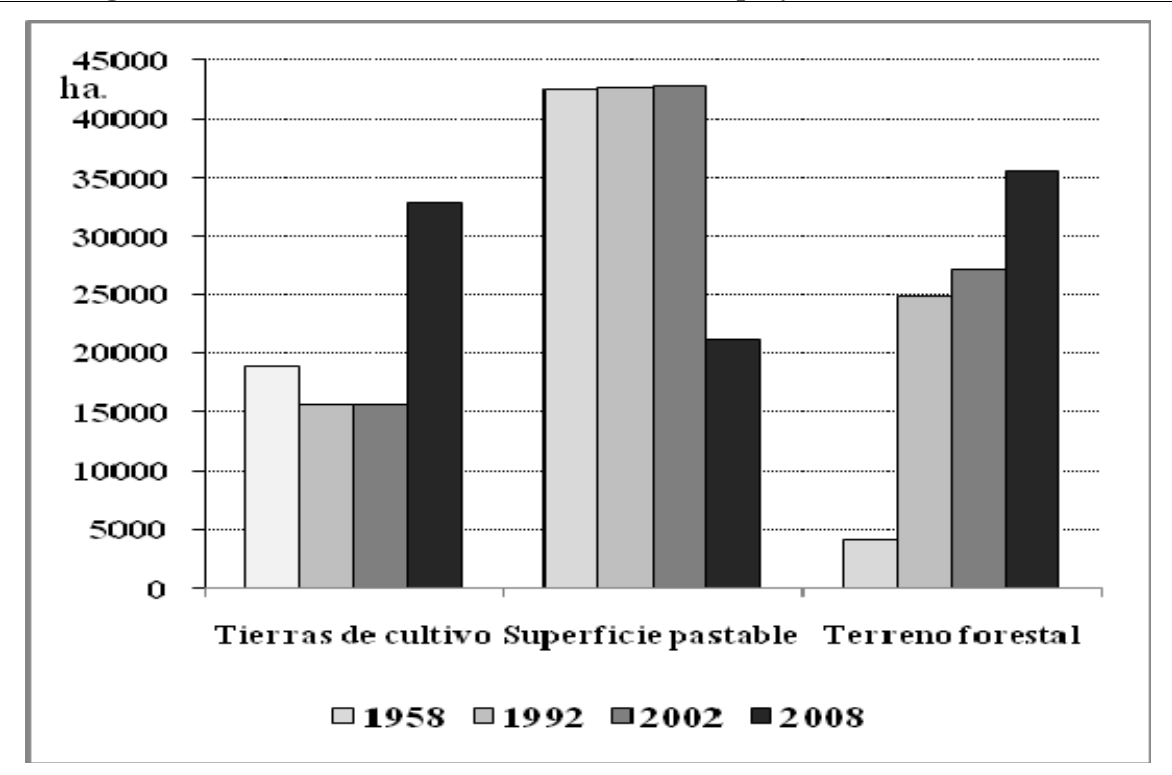

FUENTE: INE: Cámara Agraria Provincial Hojas declaratoria de superficies de cultivo, 1958. Delegación Territorial de Agricultura. Estadísticas Agrarias

Figura 5. Desarrollo del matorral en el valle del Linares y bancales abandonados en el despoblado de La Mata.
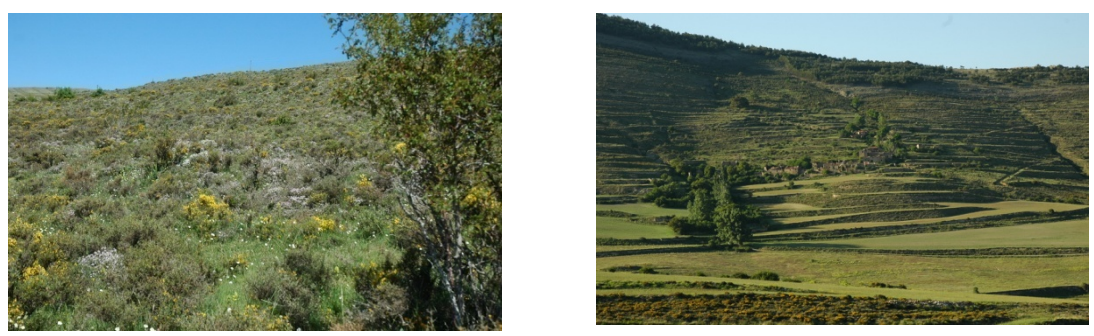

En los años 80 y, sobre todo, en los 90, es cuando se produce el hundimiento de la cabaña ganadera lanar y la reducción de la trashumancia a un puñado de ganaderos, como consecuencia de la falta de reemplazo generacional en las explotaciones. El número de cabezas de ovino/caprino pasó de 88.367 en 1982 a 
20.985 en 2002 y 18.430 en 2008 . En una comarca tan extensa, solo quedan actualmente 35 ganaderos, la mayoría con explotaciones estantes. Por su parte, la reestructuración del sector lácteo también acabó con la mayoría de las explotaciones vacunas de leche. Las 2.476 cabezas de ganado vacuno censadas en 1992 han pasado a 1.391 en el censo ganadero de 2008. Hoy quedan reducidas a solo 28 explotaciones, prácticamente todas dedicadas a la producción de carne.

Figura 6. Evolución de la ganadería ovina/caprina y vacuna en Tierras Altas.

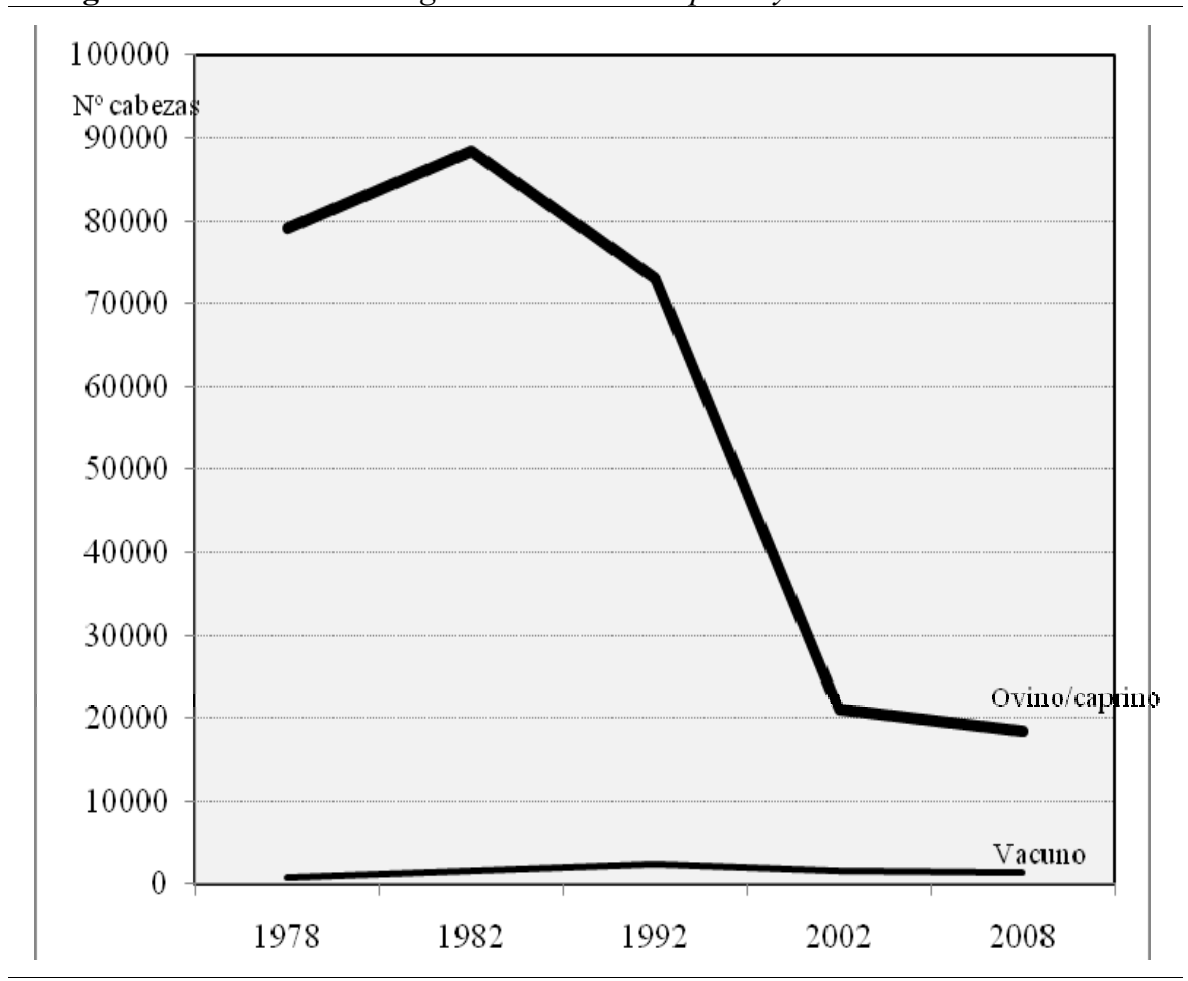

FUENTE INE: JCyL. Censos ganaderos. Elaboración propia

El descenso de la presión ganadera ha llevado a los escasos agricultores de la comarca a labrar muchas tierras de pastos y pastizales, elevando considerablemente la superficie cultivada. Debido a las imposiciones climáticas, ésta se dedicada casi al cien por cien al cultivo del cereal. Se trata de una agricultura que acusa los condicionantes climáticos y topográficos, cuya rentabilidad está supeditada al mantenimiento de las ayudas de la PAC. Las explotaciones han aumentado de tamaño, por el descenso del número de empresarios, pero tienen que trabajar sobre un parcelario muy atomizado, con un gran número de parcelas por explotación. Hay muchos términos municipales donde todavía no se ha 
realizado la concentración parcelaria en que el número de parcelas por explotación supera las 50 .

Ante el declive de las actividades agrarias tradicionales, la sociedad de Tierras Altas no supo reaccionar generando alternativas en el sector industrial, capaces de frenar la despoblación. Las condiciones climáticas y la actividad ganadera favorecían, por ejemplo, la instalación de industrias de alimentación, como ocurrió de hecho en la vecina localidad de Ólvega, conocida por su industria chacinera. Sin embargo, tan solo hay 8 empresas registradas, más de la mitad en el municipio de San Pedro Manrique, cabecera de la comarca. Se trata de pequeñas industrias artesanales, con menos de 5 trabajadores, dedicadas fundamentalmente a la fabricación de embutidos. La principal de ellas surgió en el año 1984 en el citado municipio, que da empleo a más de 50 trabajadores y mantiene una pequeña cabaña porcina -más de 31.000 cerdos- en la comarca. En el sector lácteo, según los datos de las Cámaras de Comercio e Industria, únicamente hay registrada una empresa, instalada en 1998 en la localidad de Oncala, dedicada a la fabricación de quesos y mantequilla, que cuenta con menos de 5 trabajadores en plantilla.

La consecuencia de todo ello ha sido el progresivo desmantelamiento de los servicios públicos y privados, fiel reflejo de la espiral en que está sumida la comarca. Los servicios han desaparecido de la mayoría de los municipios, concentrándose en la cabecera de comarca. Solo tres núcleos tienen servicio comercial estable y en San Pedro Manrique se reúnen las dos únicas oficinas bancarias de la comarca. Por su parte, los servicios educativos han desaparecido de todas las poblaciones y solo permanece abierto el llamado centro agrupado de Tierras Altas, situado también en la cabecera, que acoge a la mayoría de los alumnos de la comarca. Cabe decir que, paradógicamente, este centro se ha quedado pequeño ante el aumento de la población inmigrante en los últimos años.

\section{V.2. El reforzamiento económico de la comarca de Pinares}

Frente a la comarca de Tierras Altas, Pinares representa un ejemplo de adaptación a un medio hostil, con unas condiciones climáticas duras y unas dificultades de comunicación entre los distintos valles. El mantenimiento de los sistemas de aprovechamiento de la madera procedente de los montes comunales y la aparición de procesos de transformación de esta materia prima no solo ha sido un factor de estabilidad demográfica, sino que ha asegurado la pervivencia de un modelo de desarrollo bastante equilibrado y la conservación de los valores paisajísticos que atesora esta comarca serrana. En Pinares, la superficie forestal no ha dejado de crecer en las últimas décadas, a costa del pastizal y las tierras de cultivo. La única transformación reseñable procede del cambio que se produ- 
jo en el modelo de explotación del pinar durante los años 60 y 70, que provocó no pocos debates y una fuerte polémica en algunos municipios. Las nuevas ordenaciones de los montes planteaban una explotación económicamente más rentable, basada en las "cortas a hecho" o matarrasa. Este nuevo planteamiento supone para la configuración del paisaje de Pinares la presencia de rupturas en la continuidad de las masas arbóreas y la coexistencia en espacios vecinos de áreas integradas por pinos de distintas edades y distinto porte.

Las bases industriales creadas en los años 60 y 70 han servido para generar un dinamismo interno que ha sido capaz de amortiguar el éxodo rural. De gran importancia para la comarca fue la instalación en la localidad de San Leonardo de Yagüe, en el año 1955, de una importante empresa, con capital inicialmente catalán, dedicada a la fabricación de puertas, que hoy cuenta con más de 500 trabajadores, aunque ha llegado a emplear a más de 800 . En la actualidad, el número de licencias industriales existentes en la comarca se eleva a 246. A diferencia de Tierras Altas, el mapa industrial es mucho más tupido. Solo hay 6 municipios que no tengan ninguna licencia y 9 superan las 10 . En consonancia con las características de la comarca, el $86,4 \%$ de las licencias pertenecen a la rama de industrias manufactureras, de las que destaca especialmente el sector de la madera. La industria de la madera comprende 172 licencias, que representan un $71 \%$ del total de licencias industriales, y se extiende por 16 de los 23 municipios. Destaca por encima de todas la industria del aserrado de madera y fabricación de muebles, que representa más del $75 \%$ de las licencias, con un índice de cooperativismo por encima del 25\%. También cabe subrayar el tamaño de las empresas. Aunque más del $50 \%$ tienen menos de 5 trabajadores, hay un significativo $22 \%$ que cuentan entre 6 y 10 empleados y otro $22 \%$ entre 11 y 25 . Son datos que muestran el nivel de madurez alcanzado por el sistema industrial de la comarca de Pinares, plenamente arraigado en la sociedad pinariega y que debe ser puesto en valor tratándose de un espacio de montaña. Hay que tener en cuenta que casi el $40 \%$ de las licencias industriales en el sector de la madera son anteriores a 1990 .

En consonancia con la estructura económica y social de la comarca, los pueblos pinariegos gozan de un buen nivel de infraestructuras y servicios, como lo demuestra el desarrollo de las prestaciones tanto a la población como a las empresas. Los servicios comerciales cuentan con 313 licencias, repartidas en 18 de los 23 municipios. De gran tradición en la comarca pinariega son los servicios de transporte de mercancías, heredera de la antigua cabaña de carreteros, que transportaba la lana procedente de las serranías sorianas del norte de la provincia hasta los puertos de embarque del cantábrico. Para que nos demos una idea, hay actualmente 133 licencias de transporte, distribuidas en 17 municipios. También los servicios financieros son una dotación extendida por la mayoría de 
las poblaciones y otros más especializados como los servicios inmobiliarios, que cuentan con 62 y 63 licencias respectivamente.

Mayor reorganización han sufrido algunos servicios públicos, como la educación o la sanidad. Los servicios educativos se concentran en los municipios más grandes, es decir, Covaleda, Navaleno, San Leonardo de Yagüe y Quintanar de la Sierra. Las prestaciones sanitarias, en función de la política sanitaria puesta en marcha en los años 80, se distribuyen a través de tres centros de salud, situados en San Leonardo de Yagüe, Covaleda y Quintanar de la Sierra.

\section{V.3. El renovado interés por el aprovechamiento de los recursos endóge- nos: Nuevas opciones, nuevas iniciativas y nuevas respuestas ante la crisis.}

En las dos últimas décadas, las relaciones entre el mundo rural y urbano se han intensificado, en la medida que se han reforzado los vínculos económicos, se ha producido un espectacular aumento de la funcionalidad turística de los espacios rurales y se han multiplicado las posibilidades de intervención sobre el territorio. Todo ello está permitiendo opciones de uso y gestión más diversificada y, con ellas, la entrada también de nuevos intereses y nuevos conflictos, que complican el proceso de toma de decisiones, máxime en un contexto socioeconómico marcado por la situación de desesperación en la que viven muchos municipios, acuciados por la despoblación y la falta de perspectivas. La irrupción de nuevas actividades en el panorama económico del medio rural ha abierto nuevas opciones de desarrollo y ha puesto de manifiesto, a la vez, no solo la mayor o menor adaptación de los distintos territorios, sino también la capacidad de respuesta y de organización de estos ante las nuevas expectativas.

Las comarcas de Tierras Altas y Pinares no han permanecido ajenas al nuevo entorno que rodea a los espacios rurales y, singularmente, a las áreas de montaña de nuestro país. En ambos casos, se observa un renovado interés por el aprovechamiento de nuevos recursos locales y una mayor voluntad de cooperación para dar respuestas a la crisis o para luchar contra la despoblación. Dentro de las nuevas opciones, el turismo rural se ha convertido en uno de los objetivos comunes que comparten las dos comarcas para la búsqueda de nuevas oportunidades de desarrollo rural. Pero no es la única. Las energías renovables es otra de las nuevas funcionalidades que han acaparado mayor interés en los territorios rurales. Asimismo, en consonancia con los nuevos gustos del consumidor, se han desarrollado iniciativas locales en el ámbito de la producción agraria y de la industria alimentaria, algunas estrechamente relacionadas con el turismo, como es el caso de la actividad micológica, objeto de un proyecto de regulación a escala provincial y regional. Por otra parte, el boom inmobiliario de nuestro país y de otros países de nuestro entorno, ha desarrollado la industria de la madera y el 
mueble, firmemente arraigada en la comarca de Pinares, y ha despertado la puesta en marcha de nuevas posibilidades de aprovechamiento de recursos endógenos, como es el caso de la piedra natural, que ya cuenta con 9 empresas instaladas en la comarca de Pinares, especialmente en el sector burgalés.

El desarrollo de las energías renovables responde, como se sabe, a una encrucijada energética a escala global que fundamenta el diseño de las nuevas estrategias nacionales para reducir la dependencia energética y luchar, al mismo tiempo, contra el cambio climático. Nuestro país ofrecía buenas condiciones para estas nuevas formas de energía y las ha apoyado de manera decidida. Sin embargo, a nadie se le escapa que el proceso se ha desarrollado de forma indiscriminada en la mayoría de comunidades, sin hacer una valoración adecuada de los impactos paisajísticos. Esto ha ocurrido con la energía eólica en la comarca de Tierras Altas, que desde hace ocho años ha transformado el paisaje en prácticamente todos sus rincones. Desde 2001 se han instalado 10 parques eólicos, con un total de 295 aerogeneradores y una potencia de $198.000 \mathrm{Kw}$. Las diversas controversias surgidas por la instalación de los molinos son uno de los factores que impulsaron en su día la interesante idea de crear una mancomunidad que integrara a todos los municipios de Tierras Altas que voluntariamente lo desearan. Surgió así la Mancomunidad de Tierras Altas, integrada por 16 municipios, cuyo objetivo principal es salvar la impotencia funcional a la que los núcleos de población se enfrentan debido a su pequeñísimo tamaño. Participan en los beneficios de los parques eólicos, acceden a las subvenciones oficiales y con ellas están desarrollando, entre otros, un plan de dinamización turística, talleres sobre temas de alimentación y prestación de determinados servicios a los municipios asociados. Una iniciativa encomiable en un ámbito territorial y social bastante hostil como consecuencia del intenso proceso de despoblación y desarticulación socio-territorial.

Una iniciativa interesante, ésta en el sector agroalimentario, surgió en la comarca de Pinares a principios de los 90, para impulsar la ganadería vacuna. En el año 1991 se autorizó la marca de garantía de la carne de Pinares-El Valle Carpival- con el objetivo de poner en el mercado una carne de calidad. Para ello, las explotaciones debían someterse a un estricto control de las condiciones de producción, que van desde las características de raza, la alimentación y los controles en los mataderos autorizados, con vistas a asegurar la trazabilidad del producto. En los puntos de venta, esta carne tiene un etiquetado especial para asegurar al consumidor que la carne que está comprando es carne de Pinares-El Valle. Los resultados de esta iniciativa no se pueden considerar demasiado brillantes, si bien hay que tener en cuenta las crisis por las que ha pasado este sector desde entonces. La cabaña vacuna se mantuvo prácticamente estable en la comarca soriana de Pinares a lo largo de los años 90, en torno a las 3.000 cabe- 
zas, y solo se ha notado un cierto aumento en los últimos años. En el censo de 2008 se acercaban a las 4.000 cabezas, si bien el número de ganaderos ha descendido de 82 a 70 en el mismo periodo.

El boom inmobiliario de nuestro país y de otros países de nuestro entorno sí que fue un gran revulsivo para la industria de la madera en la comarca pinariega, que ha crecido en empleo y número de empresas. Entre 1996 y 2006, según datos recabados en la página web de las Cámaras de Comercio e Industria, se crearon 25 nuevas empresas en la industria de la madera. Asimismo, la década prodigiosa de la construcción residencial en nuestro país ha despertado nuevas posibilidades de aprovechamiento de recursos endógenos, como es el caso de la piedra natural. Las explotaciones de piedra arenisca, ampliamente representada en los suelos de la comarca, se ha desarrollado en los últimos 10 años, sobre todo en la parte burgalesa de Pinares. En total son 9 empresas, la mayoría surgidas entre 1994 y 2006. Todas se dedican a la extracción de piedra arenisca y algunas completan el ciclo preparándola para la construcción o para decoración. Siete de ellas se encuentran en la provincia de Burgos y hay una que cuenta con más de 100 trabajadores y con una amplia presencia en el mercado internacional. Lo más interesante es que muchas de estas empresas han surgido por iniciativa local y en base al aprovechamiento de recursos endógenos.

En la misma línea se sitúa la creación de nuevas empresas para el aprovechamiento de otros subproductos forestales, como los hongos. Son 8 empresas dedicadas a la fabricación de conservas vegetales, la mayoría surgidas en los últimos 10 años, pero que tienen, en algunos casos, una gran presencia en el mercado internacional. Cabe reseñar también el desarrollo de explotaciones de trufa negra, que cuenta con la presencia de una finca de más de 600 ha en el término de Abejar. Soria se ha convertido en una de las mayores productoras de este oro negro de la gastronomía.

El auge del turismo rural, finalmente, ha generado una reorganización de los recursos turísticos en ambas comarcas, si bien con resultados desiguales. En los dos casos se ha planteado una política de protección de espacios con interés ambiental y/o paisajístico, que ha desencadenado diversas iniciativas para enriquecer la oferta turística, en base a la creación de museos, centros de interpretación, etc. En Tierras Altas se ha declarado espacio natural al acebal de Garagüeta, en torno al cual se han desarrollado actividades organizadas y se ha constituido una asociación que intenta obtener mayor valor añadido en la comercialización de las ramas de acebo durante el periodo navideño. Pero también es interesante su rico patrimonio arquitectónico y cultural, con fiestas de prestigio internacional como el paso del fuego en San Pedro Manrique, o el museo de la trashumancia en la localidad de Oncala. También se añade las actividades relacionadas con la caza en los numerosos montes de la comarca y los que surgie- 
ron como consecuencia de las repoblaciones de los años 60 . Una actividad que mueve a un gran número de practicantes procedentes de distintas regiones y que supone resolver el problema de la estacionalidad del turismo en esta comarca de montaña. Otra iniciativa interesante en una comarca tan despoblada es la que ha surgido en torno a un pueblo abandonado, Valdelavilla, que tiene como objetivo precisamente poner en valor la despoblación. La recuperación del pueblo se orientó hace algunos años hacia la oferta de cursos de inglés. Este año se ha presentado un nuevo proyecto de creación de un complejo turístico que, sin abandonar ese segmento, pretende potenciar el turismo rural con cultura, caza y micología como principales referentes.

En la comarca pinariega, los valores naturales y paisajísticos son mucho más ricos y han fundamentado un sólido desarrollo de la actividad turística. Cuenta con varios espacios naturales declarados (cañón del río Lobos, Laguna Negra y circos glaciares de Urbión, la Fuentona, el sabinar de Calatañazor y las Lagunas de Neila) que han generado un gran crecimiento del movimiento turístico desde los años 90. La economía forestal, sometida cada vez más a los vaivenes del mercado y a una creciente competencia internacional, ha perdido peso en los últimos años, y el cobro de la llamada suerte de pinos representa ya un porcentaje muy pequeño dentro de la economía familiar. Por otra parte, la madera sufre oscilaciones de precios bastante fuertes, cuando no crisis profundas, como la que se está produciendo en los años 2009 y 2010, no solo por la crisis del sector de la construcción residencial sino también por la necesidad de venta de grandes cantidades de madera en la región francesa de las Landas, con el apoyo de la propia Unión Europea. Esto ha provocado una crisis profunda de precios, que ha repercutido muy negativamente en el nivel de ingresos de la comarca y en su sistema industrial. La crisis ha llegado también a las industrias de la piedra natural, que ha repercutido en el nivel de actividad y empleo. Sin embargo, desde hace ya más de una década se han empezado a revalorizar otros recursos que también guardaba esta comarca, entre los que destacan sus valores paisajísticos, su naturaleza y sus valores históricos y culturales. Ello ha generado un movimiento turístico de cierta entidad, que se ha convertido en un nuevo factor de desarrollo para este espacio de montaña.

El turismo, por tanto, ha pasado a ser un objetivo económico común de las dos comarcas, en base a la revalorización de los recursos locales. Sin embargo, mientras en Tierras Altas es todavía una actividad incipiente, y con grandes dificultades de difusión territorial debido a la baja población, en Pinares llevan más de una década con un desarrollo turístico significativo, que ha alcanzado además a la mayoría de los municipios. 
Figura 7. Distribución de las plazas de alojamiento.
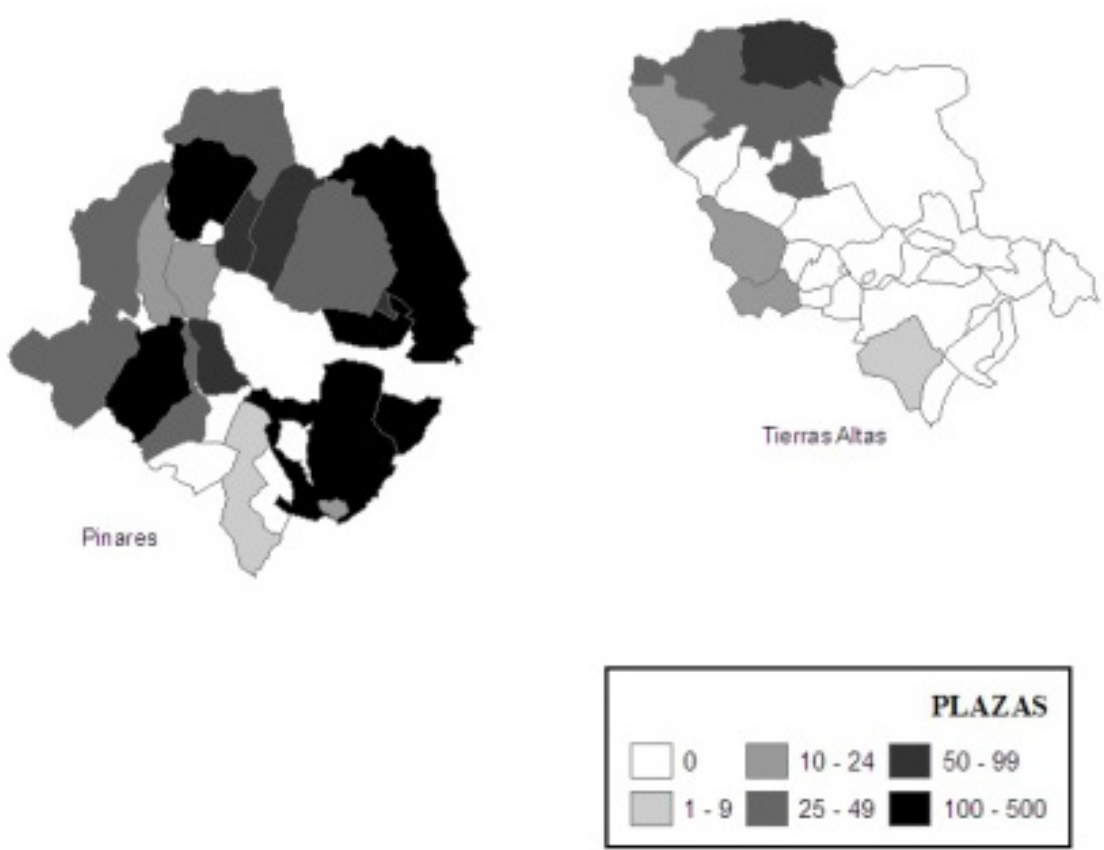

FUENTE: JCyL. Elaboración propia.

En la comarca de Pinares la capacidad de acogida asciende actualmente a 1.815 plazas, frente a las 302 de Tierras Altas. Además están distribuidas por 17 de los 23 municipios, a diferencia de Tierras Altas donde solo hay 9 núcleos que ofertan plazas de alojamiento. En Pinares hay 6 municipios que ofrecen más de 100 camas, llegándose a las 407 en el caso de Vinuesa, que es el municipio que mejor ha sabido aprovechar el tirón de la demanda turística a uno de los centros más emblemáticos de la comarca, la laguna Negra. Cabe subrayar el crecimiento que han tenido los alojamientos rurales en los últimos 15 años y su capacidad de adecuación a cualquier tamaño de población. De hecho, el aumento de la oferta en Tierras Altas está basado en el desarrollo de este tipo de alojamientos, que representan el 87,4\% de las plazas totales, frente al 34,2 en Pinares. En la primera comarca llegan a 23 las casas rurales abiertas, casi todas en régimen de alquiler, y en la segunda a 66 , también con un predominio absoluto de las casas rurales de alquiler. Las posibilidades del turismo verde en la comarca pinariega se han visto refrendadas por el éxito de los campamentos de turismo, cuyo número se ha incrementado hasta 5 , con una capacidad de de acogida de 3.675 plazas. 
El desarrollo de la funcionalidad turística no solo se aprecia en el aumento de la oferta total de alojamiento, sino también en la mejora de su calidad. Así, han aumentado el número de Posadas y Centros de Turismo Rural y, en el caso de Pinares, el número de hoteles de tres y cuatro estrellas.

\section{CONCLUSIONES}

El estudio de estos dos casos nos ha permitido descubrir los profundos contrastes existentes dentro de la montaña interior, aún en áreas muy próximas, debido a la influencia de factores agroclimáticos e históricos. La configuración del espacio derivada de los aprovechamientos tradicionales ha generado dos formas de organización bien diferentes, la de Tierras Altas, basado en la ganadería trashumante, con un modelo de poblamiento muy atomizado, y la de Pinares, basado en la explotación forestal y con un modelo de poblamiento concentrado, con pocos núcleos, pero de cierto tamaño. Los dos sistemas de aprovechamiento se han adaptado de distinta forma a los cambios que se han producido en el contexto económico y social. La crisis de la ganadería tradicional ha desencadenado un intenso proceso de éxodo rural en Tierras Altas, hasta el punto de convertirse en todo un referente en el mapa de la despoblación de la montaña interior. En Pinares el valor de la madera y la aparición de procesos de transformación de esta materia prima, con una importante presencia del cooperativismo, han sido un factor clave para el mantenimiento de un cierto dinamismo económico y de estabilidad demográfica.

El fenómeno de la despoblación ha estado sometido a una intensa literatura, pero son mucho menores las actitudes críticas. Cabria preguntarse, por ejemplo, a dónde han ido las ingentes sumas de dinero que han percibido los espacios rurales en forma de ayudas, o dónde estaban las instituciones públicas regionales cuando este proceso adquirió un carácter masivo. En Tierras Altas, el proceso de despoblación motivó la intervención del estado con la puesta en marcha en los años 60 de un ambicioso plan de reforestación, cuyos resultados han sido desiguales, aunque todavía es pronto para valorarlos en toda su extensión. El desplome de la ganadería ovina y la falta de alternativas económicas han creado una situación de desmantelamiento económico y social, que ha repercutido en el deterioro de los paisajes tradicionales. En los últimos años, la aptitud de estos montes para la producción energética ha motivado la extensión de los parques eólicos. Asimismo, han surgido iniciativas de reorganización a escala comarcal, que tratan de aprovechar nuevos recursos, como es el caso del turismo.

En la comarca de Pinares se ha logrado crear un sistema industrial entorno a los recursos forestales, que ha sido el factor clave para el sostenimiento de la población y de un cierto nivel de equipamientos y servicios en los distintos municipios. La crisis de la construcción ha hecho mella en este sistema y el futuro 
del sector no se presenta fácil. Habría que buscar alternativas para estos recursos. El aprovechamiento energético de los montes sería una de las opciones que podrían explorarse. Se puede afirmar que, a diferencia de otras áreas de montaña, la infraestructura que se ha creado en las últimas décadas constituye una buena base para poder desarrollar una explotación de otros recursos locales que, como el caso de los hongos o el turismo, albergan grandes posibilidades en esta comarca.

\section{REFERENCIAS BIBLIOGRÁFICAS}

AlCALDE JiMENEZ, José María (2000): «Señoría, trashumancia y conflictividad social en la sierra de Yanguas (siglos XVIII-XIX)», en Historia Social no 38, 73-94.

BACHILLER MARTÍNEZ, J.M. (1996): Espacios rurales desfavorecidos. Las transformaciones del suroeste soriano. Valladolid, Universidad de Valladolid, Servicio de Publicaciones.

CHANVELIER, F. (1990): La repoblación forestal en la provincia de Huesca y sus impactos geográficos. Col. Estudios Altoaragoneses n⿳30 34 .

MARTíN JIMÉNEZ, M Ma.I. (2004): «La política territorial y las áreas de montaña. El ejemplo de las zonas de montaña de Castilla y León», en Revista de Economía y Finanzas de Castilla y León, vol. 9, 99-122.

MARTíN JiMÉNEZ, Ma Isabel (2008): «Pueblos vacíos, atonía y envejecimiento en la comarca soriana de tierras Altas y valle del Tera». Ería, no 75, 113-128.

MINISTERIO DE AGRICULTURA (1965): Estudio sobre reestructuración de la comarca forestal de Yanguas y San Pedro Manrique. Inédito.

OrTega CANTERo, N. (Editor) (2006): Imágenes del paisaje. Madrid, Fundación Duques de Soria, Universidad Autónoma de Madrid.

PEREZ Romero, E. (1995): Patrimonios comunales, ganadería trashumante y sociedad en la Tierra de Soria. Valladolid, Junta de Castilla y León.

Pinillos HerRero, F. y HerRero AltelarReA, M. (2005): Implicaciones forestales, sociales y económicas de la participación de los vecinos en los aprovechamientos forestales. Desarrollo y aplicación de las ordenanzas de aprovechamientos forestales. Covaleda, julio de 2005.

PlaZA GUTIERREZ, J.I. (2008): «Las áreas de montaña en España: Balance sobre su investigación y su tratamiento en los últimos 15 años». Ería, no $75,5-26$.

Zoido NARANJo, F. y Venegas Moreno, C. (Coord.) (2002): Paisaje y ordenación del territorio. Sevilla, Fundación Duques de Soria y Junta de Andalucía. 